\title{
БЕЛЬГИЙСКИЙ ФЕДЕРАЛИЗМ КАК ФОРМА УПРАВЛЕНИЯ ЭТНОПОЛИТИЧЕСКИМИ КОНФЛИКТАМИ
}

\begin{abstract}
Аннотация. Статья посвящена рассмотрению федерализма, как формы урегулированию этнополитического конфликта в современной Бельгии. В настоящее время во многих национальных государствах усиливаются сепаратистские движения, что характерно также и для ряда стран Европейского союза. Как известно, Брюссель - это не только столица Бельгии, но и политический центр Евросоюза. Вместе с тем, усиление этнических, сепаратистских движений на Западной Европе, таких как, референдумы по независимости, прошедшие в Шотландии, Каталонии, Северной Ирландии может привести и к росту этнополитических конфликтов в ряде регионов Бельгии. Поэтому их предотвращение на территории Бельгии имеет большое значение для сохранения стабильности Европейского Союза. Методологической основой исследования является системный, структурно-функциональный, сравнительно-политический подходы, методы анализа, синтеза, индукции, дедукции, наблюдения. Автор обращает внимание на то, насколько в современных условиях важно рассмотреть опыт разрешения этнополитических конфликтов посредством бельгийской модели федерального устройства, к которой бельгийское государство перешло в конце XX века. Этот опыт важен для современных полиэтничных стран Западной Европы, так как в них потенциально могут вспыхнуть этнополитические конфликты. В статье анализируется бельгийская федеральная система в контексте управления этнополитическими конфликтами.
\end{abstract}

Ключевые слова: геополитика, Россия, мировая политика, внешняя политика США, международные отношения, дипломатия, интересы, государство, безопасность, «цветные революции».

Review: The article is devoted to the consideration of federalism as a form of ethno-political conflict management in modern Belgium. Recently separatist movements have intensified in many national states, including some EU member-states. It is known that Brussels is not only the capital of Belgium, but also the political centre of the European Union. At the same time, the increase of ethnic and separatist movements in Western Europe, as independence referendums in Scotland, Catalonia and Northern Ireland, can lead to the increase of ethno-political conflicts in some regions of Belgium. Therefore, the prevention of conflicts in Belgium is very important for the stability in the European Union. The methodology of the research is based on the systems approach, structuralfunctional and comparative-political approaches, the methods of analysis, synthesis, induction, deduction and observation. The author pays attention to the fact that at present it is very important to consider the Belgian experience of ethno-political conflicts management on the base of the federalist model which had been adopted in the country in the late 20th century. This experience is important for modern Western European countries, since they are potentially prone to ethno-political conflicts. The article analyzes Belgium's federal system in the context of ethno-political conflicts management.

Keywords: interests, geopolitics, Russia, world politics, U.S. foreign policy, international relations, diplomacy, state, security, color revolutions.

$\mathrm{B}$ Бельгии процесс перехода к федеральной системе государственного устройства осуществился в 1994 году. В первой статье Конституции Бельгии определяется, что Бельгия «федеративное государство, состоящее из сообществ и регионов». [2]

Современная Бельгия - это уникальная федерация. Согласно второй статье действующей Конституции «Бельгия включает в себя три внетерриториальных этнолингвистических сообщества: фламандское, валлонское и немецкоязычное», а в третьей статье, что «Бельгия включает в себя три автономных территориальных регионов: Фламандский, Валлонский и Брюссель». [2] Фламандцы и валлоны имеют и сообщество, и область, в то время как немцы имеют только сообщество, а
Брюссель имеет только область. Существование этих двух типов (внетерриториальные этнолингвистические сообщества и автономные территориальные регионы) приводит к «асимметричности» и способствует росту националистических и сепаратистских настроений.

Известный американский политолог А. Лейпхарт в своей книге «Демократия в многосоставных обществах» [3] предлагает термин «сообщественной демократии», который основывается на теории многосоставных демократий, которую он рассматривает на примере некоторые европейские страны, таких как Австрия, Нидерланды, Швейцария и Бельгия. По мнению А. Лейпхарда, главными признаками сообщественной демократии являются: большая коалиция, автономия сегмен- 
тов, соблюдения принципа пропорциональности и использование права вето в процессе принятия политических решений. [3] Многосоставные общества характеризуются тем, что состоят из различных составляющих сегментов, примером служит современная федеративная Бельгия, где имеются различные лингвистические сообщества: на севере - нидерландского языка, на юге - французского языка, на юго-востоке - немецкого языка и в центре страны (столица - Брюссель) - двуязычного (нидерландского и французского).

Этнополитический конфликт в Бельгии связан с появлением этнолингвистических, культурных, политических и социально-экономических проблем между фламандскими и валлонскими этническими общностями, однако на сегодняшний день они преследуют и другую цель - сепаратизм. Сепаратистское движение фламандцев оформлялось в 1979 году под управлением Влаамского блока, представляющего собой ультраправую националистическую партию, которая была создана для реализации основной цели - создания независимого государства Фландрии.

Вопреки стремлению к урегулированию конфликтной ситуации, федерализация страны не привела к консенсусу по этнополитическим проблемам. Как отмечает бельгийский политолог Мартен Тео Янс, «сама территориальная природа федерализма способствует переходу конфликта в территориальную плоскость со всеми сопутствующими такому переходу осложнениями». [11] Мартен Тео Янс отмечает, что «до тех пор, пока Брюссель представлял собой территорию, не имевшую самостоятельного политического значения, фламандцы представляли меньшинство в его населении с социологической точки зрения, но не являлись политическим меньшинством. Когда же регион Брюсселя стал одним из регионов, образующих бельгийскую федерацию, фламандское население в этом регионе превратилось в политическое меньшинство». [11] По мнению того же Мартена Тео Янса есть целесообразность замены территориального федерализма - экстерриториальным, так называемым «персональным федерализмом», который «предполагает, что получателями государственных полномочии становятся, скорее, не территории, а группы населения». [11] Именно эта идея нашла свое наиболее полное воплощение в решении вопроса о статусе Брюсселя. Оба сообщества: Фламандское и Французское полномочно обладают возможностью самостоятельно решать вопросы, связанные с жизнедеятельностью людей, составляющих данное общество.

Фламандским эквивалентом Локарнского института является аналитическая группа «In de Warande», которая объединила представителей фламандского бизнеса и интеллигенции, выражающих их интересы, поставивших перед собой задачу разработать конкретные сценарии окончательного раздела бельгийского государства. Итогом их работы стал объемный документ, опубликованный в конце 2005 года, носящий характерное название «Манифест за независимую Фландрию в единой Европе». Фактически он представляет собой решительный приговор бельгийской федерации, претендующий на научное обоснование раздельного существования двух народов. [12] В манифесте подчеркивается: имеются политические, экономические и культурные различия между фламандскими и валлонскими обществами. Два региона - Фламандский и Валлонский искусственно удерживаются властью Бельгии вместе в федеральной государственной структуре с антимажоритарными ограничениями и «хаотическим распределением полномочий». Поэтому в этой федеральной государственной структуре, невозможно проводить рациональную и эффективную политику. В связи с этим для поддержания экономической конкурентоспособности, чтобы гарантировать будущий экономический рост, приняли во внимание существующие социально-политические проблемы старение населения страны, возможные негативные последствия глобализации. Во фламандском обществе стали часто звучать высказыванием о том, что необходимо отделиться от Бельгии и заняться строительством собственного независимого суверенного государства для разрешения имеющихся этнополитических проблем.

После парламентских выборов 10 июня 2007 года, лидер партии фламандских христианских демократов (Christien - Democratisch en Vlaams $\mathrm{CD} \& \mathrm{~V})$, бывший Премьер-министр Фландрии Ив Летерм в течение шесть месяцев не мог сформировать правительство. «Яблоком раздора» между потенциальными партнерами по правительственной коалиции изначально стало предложение Ив Летерма о предоставлении большей самостоятельности бельгийским регионам. Он предложил, в частности, отказаться от действующей государственной практики, согласно которой прерогатива решать, какие ограниченные полномочия могут иметь регионы, принадлежит федеральному правительству и парламенту Бельгии. Оба этих института, по мнению Ив Летерма, должны, напротив, находиться «на службе» у региональных властей. [9] Политический кризис происшедший в Бельгии в 2007 году сопровождался усилением воздействия и возрастанием численности сепаратистов среди фламандцев.

Известный американский исследователь национализма Уолкер Коннор подчеркивает, что «многонациональное государство сталкивается с 
двойной угрозой, состоящей из требований самоопределения снизу и правительственных программ ассимиляции сверху. Поэтому современные политические силы отчетливо двигаются в сторону пророчества Баркера, который предвидел мировой порядок, в котором «каждое государство является и нацией». [8] С этой точки зрения можно сказать, что федерализм играет позитивную роль в управлении этнополитическими конфликтами в многосоставном обществе. Для того, чтобы ликвидировать этнические различии в XX веке некоторые страны порой применяли насилие, всё ради сохранения преобладающего влияния доминирующей нации или этнической группы. Как подчеркивают ирландский политолог, профессор Лондонской школы экономики и политических наук Брендон О’Лири и профессор Канадского исследовательского центра по национализму и демократии в Королевском университете в Канаде Джон Мак Гэрри «здесь не было смерти нации-государства, однако было много смертей в войне нации против государства, государства против нации и одной нации против другой нации». [6]

Английский философ и социальный антрополог А. Эрнест Геллнер считает, что если бы большинство полиэтнических или многонациональных государств мира уже находились бы в стадии исчезновения или представляли собой чистую фикцию, то в результате этого человечество уже давно бы быстрыми шагами двигалась в направлении «одна нация, одно государство». [5]

Теоретически бельгийская модель уникального федерализма должна была привести к разрешению этнополитического конфликта. Однако его принципы не в полной мере привели к снятию противоречий. Особое внимание в разрешении этнополитического конфликта в Бельгии придается современному характеру международных связей регионов бельгийского государства. Многоступенчатые согласования делают бельгийский федерализм сложным для функционирования, что заметно замедляет скорость принятия политических решений. Политический кризис, который сотрясал Бельгию в 2007 году, может служить доказательством этого. В связи с особое значение имеет соотношении федерализма и национализма в современном мире.

Необходимо отметить, что, несмотря на целый ряд политических реформ и, в конце концов, принятие федерализации страны, она не устраняет полностью межэтнические противоречия. Однако федерализм позволяет ослабить националистические тенденции. В основе национализма лежит философия, в соответствии с которой нация «должна быть коллективно и свободно выражена институционально и управляться своими представителя- ми». [13] Это определение близко к классической формулировке Эрнста Геллнера, в соответствии с которой национализм - это «прежде всего политический принцип, который базируется на утверждении что политическая и национальная единицы должны совпадать». [5] В обоих определениях нет ничего, что делало бы национализм несовместимым с федерализмом, федеративной политической системой или с федерацией как таковой. Коллективно и свободно выраженная институционально воля более чем одной нации, в принципе, вполне возможна в рамках федерации. Федерация может быть организована таким образом, чтобы имелось «совпадение» между каждой региональной и национальной единицей, то есть, чтобы каждый регион мог иметь свою титульную нацию. Известный российский этнолог Тишков В.А. констатирует, что существуют четыре типа ситуаций, при которых федерализм оказывается перед вызовом этнического фактора; один из их - федерации в хроническом кризисе, например Бельгия. [4]

Опасность сецессии в многонациональных федерациях столь велика, что еще в 1972 году американский социолог Эрик А. Нордлингер вообще исключил федерализм из списка желательных мер по регулированию конфликтов [7].

Кроме того, важно принимать во внимание необходимость сотрудничества как между отдельным субъектом федерации и центральным правительством, так и между различными регионами. Асимметрия федеративных отношений порождает сложности, так как остальные субъекты федерации стремятся к получению полноты власти региона, которое занимает привилегированное положение.

Бельгийский федерализм несет в себе и большой политический заряд, который может взорвать страну изнутри в любой момент, когда это понадобится европейской бизнес - элите. После парламентских выборов 2010 года фламандские и валлонские социалисты целых 18 месяцев формировали Бельгийское правительство. На выборах 2014 года наибольшее количество голосов досталось представителям фламандского национализма в лице партии «Новый фламандский альянс», во главе со Бартом де Вевером. Кстати, Барт де Вевер в 2008 году сравнил франкоязычных жителей Фландрии с гастарбайтерами из зарубежных стран, заявив, что «во Фландрии нет меньшинств, но есть только иммигранты». [10]

С федерализацией страны стало наблюдаться некоторое отчуждение в социально-экономическом развитии между регионами Бельгии. Реакция валлонского общественного мнения на «фламандский манифест» вызвала в обществе гнев и раздражение. [12] Федерализация страны является наиболее значимым факторам для сохранения 
целостности государства, однако опыт Бельгии показывает размежевание политических партий на этнической основой. В связи с этим каждая партия стремится отстаивать интересы своих этнических групп.

В последнее время в некоторых западноевропейских странах тема сепаратизма приобретает чрезвычайную популярность. Наряду с сепаратистки настроенными регионами, такими, как Фламандия в Бельгии, так же вызывают большую озабоченность и тревогу Шотландия в Великобритании, Каталония в Испании, Венеция в Италии. Особое пристальное внимание в этих странах уделяется результатам национального референдума о независимости Шотландии, который был проведен 18 сентября 2014 года. Важным событием также стало принятие резолюций региональным парламентом в Каталонии 27 сентября 2015 года и 09 ноября 2015 года о выходе из состава Испании.

Однако, несмотря на отмеченные выше недостатки, опыт решения этнополитических проблем бельгийской федеральной системой вызывает не поддельный интерес у мировой общественности, так как имеет значение и для остальной части континентальной Европы. [1] С одной стороны, благодаря федеральной системе в Бельгии стали возможными согласование и баланс сил в парламенте, a также учёт интересов различных этнических групп, а с другой стороны, существование королевской власти, как объединяющего символа и традиции позволяет сохранить идентичность бельгийцев и единство страны. В случае же с двуязычным регионом Бельгии - Брюсселем, где действуют уравновешивающие друг друга этнополитические силы, которые являются преградой для возникновения политического противостояния, политического кризиса в регионе.

Бельгийская федеральная система является «опытной лабораторией» [1] для современных федеральных образований в странах Западной Европы в вопросе разрешения этнополитических конфликтов. Федерализм эффективно используется для разрешения этнополитических проблем в полиэтничных странах. Большинством экспертов считается, что федерализация Бельгии это средство для сохранения общественного мира в стране. Опыт Бельгии демонстрирует мировому сообществу возможности урегулирования этнополитических противоречий путем параллельного формирования этнической и гражданской идентичности.

На процесс формирования и развития фламандского движения оказывала сильное влияние и требования языковой и культурной автономии. На самом деле, важным положением, моментом мобилизации фламандского сообщества явилось его желание, стремление к распространению и разви- тию собственного языка и культуры. Валлонское движение в Бельгии, возникло с требованиями регионального самоуправления на экономических и социальных основаниях. Однако, во второй половине XX века Фландрия достигла экономическое превосходство над Валлонией. В связи с этим изменением социально-экономического положения в стране началось усиление на фламандском национальном движений.

Таким образом, исполнение следовавших друг за другом реформ государственного устройства для мирного урегулирования этнополитических конфликтов, способствовало тому, что Бельгия стала федеративным государством. Разногласия в Бельгии по вопросам этнополитического развития были разрешены благодаря предоставлению властями автономии фламандцам и валлонам, и принятию для административного управления в своих регионах, сообществах соответствующих языков.

Неравномерность социально-экономического развития регионов стран Западной Европы вызывает недовольство в богатых регионах, которые не желают кормить бедные провинций в своих странах, например, Шотландия в Великобритании, Страна Басков и Каталония в Испании, Фландрия в Бельгии и т.д. Это неравномерность распределения доходов создает почву для сепаратизма в континентальной Европе. Несомненно, что в таких случаях усиления этнополитических противоречий в Бельгии и активизирования фламандского сепаратистского движения будут являться стимулирующие факторы для других этнополитических кризисов в странах Западной Европы.

Необходимо отметить, что стабильность Бельгии имеет важное стратегическое значение для континентальной Европы, так как она является политическим центром Европейского Союза. Брюссель - столица не только Бельгии, но и Евросоюза. Наряду с этим штаб-квартира Североатлантического Альянса (НАТО) находится в Брюсселе. Если будет возникнуть неразрешимая этнополитическая кризисная ситуация в Бельгии, это может стать новой проблемой для НАТО и ЕС. С другой стороны, необходимо обращать внимание на то, что этническое большинство города - франкофоны.

Центробежная модель федерализации в Бельгии стала действенным способом управления этнополитическими конфликтами, которые не могли быть решены в рамках унитарного устройства государства. Благодаря этой системе стало возможным исключать случаи возникновения перманентных массовых беспорядков и активной деятельности сепаратистов, имеющихся в таких регионах, как Северная Ирландия, Шотландия, Каталония и Страна Басков. 


\section{Библиография:}

1. Карсанова Е.С. Этнополитические конфликты в многонациональных государствах: компаративный анализ. Монография / Е.С. Карсанова. - Одинцово: «АНОО ВПО ОГИ», 2010. - 231с.

2. Конституция Бельгии. Принята 17 февраля 1994 года http://www. worldconstitutions.ru

3. Лейпхарт А. Демократия в многосоставных обществах. - М.: «Аспект Пресс», 1997. - 287c.

4. Тишков В.А. Этнический Федерализм: российский и международный опыт // Тишков В.А. Этнология и политика. М.: «Наука», 2001. 240с.

5. Gellner E. Nationalism. - New York: «Weidenfeld \& Nicolson», - 1997.

6. McGarry J. and O [Leary B. The Politics of Ethnic Conflict Regulation. - New York: «Routledge»,-1993.]

7. Nordlinger E. Conflict Regulation in Divided Societies. - Cambridge, MA: «Center for International Affairs, Harvard University»,-1972.

8. Connor W. Ethnonationalism: the Quest for Understanding. - «Princeton University Press». 1994.

9. Бельгия, переживающая острый политический кризис, пытается избежать раскола. Время публикации: 14 сентября 2007 г. http://www.newsru.com/world/14sep2007/ belgium.html

10. Куприянов А. Бельгийский полураспад. Феодальный кризис XXI века. http://lenta. ru/articles/2014/09/30/belgium/

11. Янс М.Т. Персональный федерализм: решение для этнонациональных конфликтов? Что он означал для Брюсселя и что он мог означать для Абхазии? // http://www.poli.vub.ac. be/publi/orderbooks/federal_r/16jans.pdf

12. Mnookin Robert, Alain Verbeke. Persistent Nonviolence Conflict With No Reconciliation: The Flemish and Walloons In Belgium. // Law and Contemporary Problems. Volume: 72; 151. - 2009. - P.151-186. http:// scholarship.law.duke.edu/ cgi/viewcontent.cgi? article=1524\&context=lcp

13. O [Leary B. On the Nature of Nationalism: An Appraisal of Ernest Gellner] s Writings on Nationalism. // British Journal of Political Science. - 1997 - №27 - PP.191-222. http://www.polisci.upenn.edu/ppec/PPEC\%20People /Brendan \%20 O’Leary /publications/Journa 1\%20Articles/Oleary_BJPS_Appraisal_Gellner.pdf

14. Гушер А.И. Вызовы и угрозы безопасности России // Мировая политика. - 2014. - 1. - C. 64 - 75. DOI: 10.7256/24098671.2014.1.10748. URL: http://www.e-notabene.ru/wi/article_10748.html

15. Семченков А.С. Военные угрозы безопасности государств в условиях глобализации // Конфликтология / пота bene. - 2015. - 3. - C. 292 - 304. DOI: 10.7256/2409-8965.2015.3.14334.

16. Карпович О.Г. Современные концепции и модели управления международными конфликтами (сравнительный политологический анализ) // Национальная безопасность / nota bene. - 2013. - 4. - C. 605 - 612. DOI: 10.7256/20738560.2013.4.6434.

17. Манойло А.В. Геополитическая картина современного мира и управляемый хаос // Мировая политика. - 2015. 1. - C. 66 - 80. DOI: 10.7256/2409-8671.2015.1.12665. URL: http://www.e-notabene.ru/wi/article_12665.html

18. Будаев А.В. Основные подходы к использованию «мягкой силы» в интересах реализации внешней политики Российской Федерации // Тренды и управление. - 2014. - 2. - С. 175 - 187. DOI: 10.7256/2307-9118.2014.2.11784.

\section{References (transliterated):}

1. Karsanova E.S. Etnopoliticheskie konflikty v mnogonatsional'nykh gosudarstvakh: komparativnyi analiz. Monografiya / E.S. Karsanova. - Odintsovo: «ANOO VPO OGI», 2010. - 231s.

2. Konstitutsiya Bel'gii. Prinyata 17 fevralya 1994 goda http://www. worldconstitutions.ru

3. Leipkhart A. Demokratiya v mnogosostavnykh obshchestvakh. - M.: «Aspekt Press», 1997. - 287s.

4. Tishkov V.A. Etnicheskii Federalizm: rossiiskii i mezhdunarodnyi opyt // Tishkov V.A. Etnologiya i politika. M.: «Nauka», 2001. 240s.

5. Gellner E. Nationalism. - New York: «Weidenfeld \& Nicolson», - 1997.

6. McGarry J. and O [Leary B. The Politics of Ethnic Conflict Regulation. - New York: «Routledge»,-1993.]

7. Nordlinger E. Conflict Regulation in Divided Societies. - Cambridge, MA: «Center for International Affairs, Harvard University»,-1972.

8. Sonnor W. Ethnonationalism: the Quest for Understanding. - «Princeton University Press». - 1994.

9. Bel'giya, perezhivayushchaya ostryi politicheskii krizis, pytaetsya izbezhat' raskola. Vremya publikatsii: 14 sentyabrya 2007 g. http://www.newsru.com/world/14sep2007/ belgium.html

10. Kupriyanov A. Bel'giiskii poluraspad. Feodal'nyi krizis XXI veka. http://lenta. ru/articles/2014/09/30/belgium/

11. Yans M.T. Personal'nyi federalizm: reshenie dlya etnonatsional'nykh konfliktov? Chto on oznachal dlya Bryusselya i chto on mog oznachat' dlya Abkhazii? // http://www.poli.vub.ac. be/publi/orderbooks/federal_r/16jans.pdf

12. Mnookin Robert, Alain Verbeke. Persistent Nonviolence Conflict With No Reconciliation: The Flemish and Walloons In Belgium. // Law and Contemporary Problems. Volume: 72; 151. - 2009. - P.151-186. http:// scholarship.law.duke.edu/ cgi/viewcontent.cgi? article=1524\&context=lcp

13. O [Leary B. On the Nature of Nationalism: An Appraisal of Ernest Gellner] s Writings on Nationalism. // British Journal of Political Science. - 1997 - №27 - PP.191-222. http://www.polisci.upenn.edu/ppec/PPEC\%20People /Brendan \%20 O’Leary /publications/Journa 1\%20Articles/Oleary_BJPS_Appraisal_Gellner.pdf

14. Gusher A.I. Vyzovy i ugrozy bezopasnosti Rossii // Mirovaya politika. - 2014. - 1. - C. 64 - 75. DOI: 10.7256/24098671.2014.1.10748. URL: http://www.e-notabene.ru/wi/article_10748.html

15. Semchenkov A.S. Voennye ugrozy bezopasnosti gosudarstv v usloviyakh globalizatsii // Konfliktologiya / nota bene. 2015. - 3. - C. 292 - 304. DOI: 10.7256/2409-8965.2015.3.14334.

16. Karpovich O.G. Sovremennye kontseptsii i modeli upravleniya mezhdunarodnymi konfliktami (sravnitel'nyi politologicheskii analiz) // Natsional'naya bezopasnost' / nota bene. - 2013. - 4. - C. 605 - 612. D0I: 10.7256/20738560.2013.4.6434.

17. Manoilo A.V. Geopoliticheskaya kartina sovremennogo mira i upravlyaemyi khaos // Mirovaya politika. - 2015. - 1. C. 66 - 80. DOI: 10.7256/2409-8671.2015.1.12665. URL: http://www.e-notabene.ru/wi/article_12665.html

18. Budaev A.V. Osnovnye podkhody k ispol'zovaniyu «myagkoi sily» v interesakh realizatsii vneshnei politiki Rossiiskoi Federatsii // Trendy i upravlenie. - 2014. - 2. - C. 175 - 187. DOI: 10.7256/2307-9118.2014.2.11784. 